\title{
On approximation of fixed points of multivalued pseudocontractive mappings in Hilbert spaces
}

Felicia Obiageli Isiogugu*

\section{"Correspondence:}

felicia.isiogugu@unn.edu.ng School of Mathematics, Statistics and Computer Sciences, University of KwaZulu-Natal, Westville Campus, Durban, 4000, South Africa Department of Mathematics, University of Nigeria, Nsukka, Nigeria

\section{Springer}

\begin{abstract}
It is proved that if a multivalued $k$-strictly pseudocontractive mapping $S$ of Chidume et al. (Abstr. Appl. Anal. 2013:629468, 2013) is of type one, then I - S is demiclosed at zero. Also, under this condition, the Mann (respectively, Ishikawa) sequence weakly (respectively, strongly) converges to a fixed point of a multivalued k-strictly pseudocontractive (respectively, pseudocontractive) mapping $S$ without the condition that the fixed point set of $S$ is strict, where $S$ is of type one if for any pair $r, g \in D(S)$,

$$
\|u-v\| \leq \Phi(S r, S g) \quad \text { for all } u \in P_{S} r, v \in P_{S} g
$$

and $\Phi$ denotes the Hausdorff metric. The results obtained give a partial answer to the problem of the removal of the strict fixed point set condition, which is usually imposed on multivalued mappings. Thus, the results extend, complement, and improve the results on multivalued and single-valued mappings in the contemporary literature.
\end{abstract}

MSC: $47 \mathrm{H} 10 ; 54 \mathrm{H} 25$

Keywords: Hilbert spaces; $k$-strictly pseudocontractive mappings; pseudocontractive mappings; demiclosedness; type one

\section{Introduction}

The approximation of fixed points of multivalued mappings with respect to the Hausdorff metric, using Mann [2] or Ishikawa [3] iteration scheme, has never been successful without imposing the condition that either the fixed point set of $S$ is strict or that $S$ is a multivalued mapping for which $P_{S}$ satisfies some contractive conditions (see, e.g., $[1,4-$ 9], and references therein). Among these recent studies, Chidume et al. [1] introduced the class of multivalued pseudocontractive mappings as follows.

Definition 1.1 ([1]) Let $H$ be a real Hilbert space. A multivalued mapping $S: D(S) \subseteq H \rightarrow$ $C B(H)$ from the domain of $S$ into the family of all closed and bounded subsets of $H$ is said to be $k$-strictly pseudocontractive in the sense of Chidume et al. [1] if there exists $k \in(0,1)$

(c) 2016 Isiogugu. This article is distributed under the terms of the Creative Commons Attribution 4.0 International License (http://creativecommons.org/licenses/by/4.0/), which permits unrestricted use, distribution, and reproduction in any medium, provided you give appropriate credit to the original author(s) and the source, provide a link to the Creative Commons license, and indicate if changes were made. 
such that

$$
\Phi^{2}(S r, S g) \leq\|r-g\|^{2}+k\|r-u-(g-v)\|^{2} \quad \text { for all } u \in S r, v \in S g
$$

If $k=1$, then $S$ is said to be pseudocontractive. Also, they proved some weak and strong convergence theorems for this class of mappings using the condition that either the fixed point set of $S$ is strict or $S$ is a multivalued mapping such that $P_{S}$ is pseudocontractive. They proved the following theorems.

Theorem 1.1 ([1]) Let C be a nonempty, closed, and convex subset of a real Hilbert space $H$, and let $S: C \rightarrow P(C)$ be a multivalued mapping such that $F(S) \neq \emptyset$. Assume that $P_{S}$ is $k$ strictly pseudocontractive. Let $\left\{r_{n}\right\}$ be a sequence defined iteratively from arbitrary point $r_{1} \in C$ by

$$
r_{n+1}=(1-\lambda) r_{n}+\lambda g_{n}
$$

where $g_{n} \in P_{S} r_{n}$ and $\lambda \in(0,1-k)$. Then, $\lim _{n \rightarrow \infty} d\left(r_{n}, S r_{n}\right)=0$.

Theorem 1.2 ([1]) Let $C$ be a nonempty, closed, and convex subset of a real Hilbert space $H$, and let $S: C \rightarrow P(C)$ be a multivalued $k$-strictly pseudocontractive mapping with $F(S) \neq \emptyset$ such that for every $r \in C$, Sr is weakly closed and $S z=\{z\}$ for all $z \in F(S)$. Suppose that $S$ is hemicompact. Let $\left\{r_{n}\right\}$ be a sequence defined iteratively from arbitrary point $r_{0} \in C$ by

$$
r_{n+1}=(1-\lambda) r_{n}+\lambda g_{n}
$$

where $g_{n} \in P_{S} r_{n}$ and $\lambda \in(0,1-k)$. Then, the sequence $\left\{r_{n}\right\}$ strongly converges to a fixed point of $S$.

Recently, Isiogugu et al. [10] observed that there are multivalued Lipschitzian maps with nonempty fixed point set for which neither the fixed point set of $S$ is strict nor $P_{S}$ satisfies any of the contractive conditions studied so far by authors. They also noted that these classes of maps have another interesting property of some existing maps considered recently by authors (see, e.g., $[1,4-9,11,12]$, and references therein). They therefore suggested to approximate the fixed points of multivalued mappings $S$ directly instead of $P_{S}$ and without imposing the strict fixed point set condition on $S$. This suggestion was also due to the fact that it has not been established that if a multivalued map $S$ belongs to a class of maps, then $P_{S}$ necessarily belongs to the same class of maps and that the fixed point set of $S$ need not be strict. Consequently, they introduced the 'type-one' condition, which guarantees the weak convergence of the Mann sequence $\left\{r_{n}\right\}$ without imposing the condition that the fixed point set of $S$ is strict to a fixed point of a multivalued quasinonexpansive mapping $S$ in a real Hilbert space. They also proved that under this condition, if $S$ is nonexpansive, then $I-S$ is demiclosed at zero. They obtained the following results.

Proposition 1.1 ([10]) Let $H$ be a real Hilbert space, and $C$ a nonempty weakly closed subset of $H$. Let $S: C \subseteq H \rightarrow P(H)$ be a multivalued mapping from $C$ into the family of all proximinal subsets of $H$. Suppose that $S$ is a nonexpansive mapping of type one. Suppose 
that $\left\{r_{n}\right\}_{n=1}^{\infty} \subseteq C$ is such that $\left\{r_{n}\right\}$ weakly converges to $p$ and a sequence $\left\{g_{n}\right\}$ with $g_{n} \in S r_{n}$ and $\left\|r_{n}-g_{n}\right\|=d\left(r_{n}, S r_{n}\right)$ for all $n \in \mathbb{N}$ is such that $\left\{r_{n}-g_{n}\right\}$ strongly converges to 0 . Then $0 \in(I-S) p$ (i.e., $p=v$ for some $v \in S p)$.

Theorem 1.3 ([10]) Let C be a nonempty closed and convex subset of a real Hilbert space $H$. Suppose that $S: C \rightarrow P(C)$ is a type-one nonexpansive mapping from $C$ into the family of all proximinal subsets of $C$ such that $F(S) \neq \emptyset$. Then the Mann-type sequence defined by

$$
r_{n+1}=\left(1-\mu_{n}\right) r_{n}+\mu_{n} g_{n}
$$

weakly converges to $q \in F(S)$, where $g_{n} \in S r_{n}$ with $\left\|r_{n}-g_{n}\right\|=d\left(r_{n}, S r_{n}\right)$ and $\mu_{n} \subseteq(0,1)$ satisfying $\mu_{n} \rightarrow \mu \in(0,1)$.

Theorem 1.4 ([10]) Let C be a nonempty closed and convex subset of a real Hilbert space $H$. Suppose that $S: C \rightarrow P(C)$ is a type-one quasi-nonexpansive mapping from $C$ into the family of all proximinal subsets of C. If $(I-S)$ satisfies Proposition 1.1, then the Mann-type sequence defined by

$$
r_{n+1}=\left(1-\mu_{n}\right) r_{n}+\mu_{n} g_{n}
$$

weakly converges to $q \in F(S)$, where $g_{n} \in S r_{n}$ with $\left\|r_{n}-g_{n}\right\|=d\left(r_{n}, S r_{n}\right)$ and $\mu_{n} \subseteq(0,1)$ satisfying $\mu_{n} \rightarrow \mu \in(0,1)$.

Therefore, our purpose in this work is to establish that the type-one condition introduced by Isiogugu et al. [10] guarantees the weak (respectively, strong) convergence of the Mann (respectively, Ishikawa) sequence $\left\{r_{n}\right\}$ to a fixed point of $k$-strictly pseudocontractive (respectively, pseudocontractive) mapping $S$ of Chidume et al. [1] without the condition that the fixed point set of $S$ is strict in a real Hilbert space. It is also proved that, under this condition, $I-S$ is demiclosed at zero if $S$ is $k$-strictly pseudocontractive. The results obtained extend, complement, and improve the results on multivalued and single-valued mappings and also give a partial solution to the problem of removing the strict fixed point set condition usually imposed on $S$.

\section{Preliminaries}

In the sequel, we shall need the following definitions and lemmas.

Definition 2.1 Let $X$ be a nonempty set, and let $S: X \rightarrow X$ be a map. A point $r \in X$ is called a fixed point of $S$ if $r=S r$. If $S: X \rightarrow 2^{X}$ is a multivalued map, then $r$ is a fixed point of $S$ if $r \in S r$. If $S r=\{r\}$, then $r$ is called a strict fixed point of $S$. The set $F(S)=\{r \in D(S)$ : $r \in S r\}$ (respectively, $F(S)=\{r \in D(S): r=S r\}$ ) is called the fixed point set of a multivalued (respectively, single-valued) map $S$, whereas the set $F_{S}(S)=\{r \in D(S): S r=\{r\}\}$ is called the strict fixed point set of $S$.

Definition 2.2 Let $X$ be a normed space. A subset $C$ of $X$ is said to be proximinal if given any $r \in X$, there exists $k \in C$ such that

$$
\|r-k\|=\inf \{\|r-g\|: g \in C\}=d(r, C) .
$$


It is well known that every closed convex subset of a uniformly convex Banach space is proximinal. For a nonempty set $X$, we shall denote the family of all nonempty closed and bounded subsets of $X$ by $C B(X)$, the family of all nonempty closed, convex, and bounded subsets of $X$ by $C V B(X)$, the family of all nonempty closed subsets of $X$ by $C(X)$, the family of all proximinal subsets of $X$ by $P(X)$, and the family of all nonempty subsets of $X$ by $2^{X}$.

Definition 2.3 Let $\Phi$ denote the Hausdorff metric induced by the metric $d$ on $X$, that is, for all $A, B \in C B(X)$,

$$
\Phi(A, B)=\max \left\{\sup _{a \in A} d(a, B), \sup _{b \in B} d(b, A)\right\} .
$$

Definition 2.4 Let $X$ be a normed space. Let $S: D(S) \subseteq X \rightarrow 2^{X}$ be a multivalued mapping on $X$. $S$ is called $L$-Lipschitzian if there exists $L \geq 0$ such that, for all $r, g \in D(S)$,

$$
\Phi(S r, S g) \leq L\|r-g\|
$$

If $L \in[0,1)$ in (2.1), then $S$ is said to be a contraction, whereas $S$ is nonexpansive if $L=1$. $S$ is called quasi-nonexpansive if $F(S)=\{r \in D(S): r \in S r\} \neq \emptyset$ and, for all $z \in F(S)$,

$$
\Phi(S r, S z) \leq\|r-z\|
$$

Clearly, every nonexpansive mapping with nonempty fixed point set is quasi-nonexpansive. $S$ is said to be $k$-strictly pseudocontractive in the sense of Chidume et al. [1] if there exists $C \in(0,1)$ such that

$$
\Phi^{2}(S r, S g) \leq\|r-g\|^{2}+k\|r-u-(g-v)\|^{2} \quad \text { for all } u \in S r, v \in S g .
$$

If $k=1$ in (2.3), then $S$ is said to be pseudocontractive. $S$ is said to be of $k$-strictly pseudocontractive type in the sense of Isiogugu [5] if there exists $k \in(0,1)$ such that given any pair $r, g \in D(S)$ and $u \in S r$, there exists $v \in S g$ satisfying $\|u-v\| \leq \Phi(S r, S g)$ and

$$
\Phi^{2}(S r, S g) \leq\|r-g\|^{2}+k\|r-u-(g-v)\|^{2} .
$$

If $k=1$ in (2.4), then $S$ is said to be of pseudocontractive type. It is easy to see that any proximinal, pseudocontractive map $S$ of Chidume et al. [1] is of pseudoconytractive type in the sense of Isiogugu [5].

Definition 2.5 ([13,14]) Let $X$ be a Banach space. Let $S: D(S) \subseteq X \rightarrow 2^{X}$ be a multivalued mapping. Then $I-S$ is said to be weakly demiclosed at zero if for any sequence $\left\{r_{n}\right\}_{n=1}^{\infty} \subseteq$ $D(S)$ such that $\left\{r_{n}\right\}$ converges weakly to $z$ and a sequence $\left\{g_{n}\right\}$ with $g_{n} \in S r_{n}$ for all $n \in \mathbb{N}$ such that $\left\{r_{n}-g_{n}\right\}$ strongly converges to zero, we have $z \in S z(i . e ., 0 \in(I-S) z)$.

Definition 2.6 ([15]) A Banach $X$ is said to satisfy Opial's condition if whenever a sequence $\left\{r_{n}\right\}$ converges weakly to $r \in X$, we have

$$
\liminf \left\|r_{n}-r\right\|<\liminf \left\|r_{n}-g\right\|
$$

for all $g \in X, g \neq r$. 
Definition $2.7([13,14])$ Let $X$ be a Banach space, and $S: D(S) \subseteq X \rightarrow 2^{X}$ a multivalued mapping. The graph of $I-S$ is said to be closed in $\sigma\left(X, X^{*}\right) \times(X,\|\cdot\|)$ (i.e., $I-S$ is weakly demiclosed or demiclosed) if for any sequence $\left\{r_{n}\right\}_{n=1}^{\infty} \subseteq D(S)$ such that $\left\{r_{n}\right\}$ weakly converges to $z$ and a sequence $\left\{g_{n}\right\}$ with $g_{n} \in S r_{n}$ for all $n \in \mathbb{N}$ such that $\left\{r_{n}-g_{n}\right\}$ strongly converges to $g$, we have $g \in(I-S) z$ (i.e., $g=z-v$ for some $v \in S z$ ). Here $I$ denotes the identity on $X, \sigma\left(X, X^{*}\right)$ is the weak topology of $X$, and $(X,\|\cdot\|)$ is the norm (or strong) topology of $X$.

Definition 2.8 ([6]) A multivalued mapping $S: C \rightarrow P(C)$ is said to satisfy condition (1) (see, e.g., [6]) if there exists a nondecreasing function $f:[0, \infty) \rightarrow[0, \infty)$ with $f(0)=0$ and $f>0$ on $(0, \infty)$ such that

$$
d(r, S r) \geq f(d(r, F(S)), \quad \forall r \in C
$$

Definition 2.9 ([10]) Let $X$ be a normed space, and $S: D(S) \subseteq X \rightarrow 2^{X}$ be a multivalued map. $S$ is said to be of type one if given any pair $r, g \in D(S)$, we have

$$
\|u-v\| \leq \Phi(S r, S g) \quad \text { for all } u \in P_{S} r, v \in P_{S} g
$$

Lemma 2.1 Let $H$ be a real Hilbert space, and $\left\{r_{n}\right\}_{n=1}^{\infty}$ a sequence in $H$ weakly converging to $z \in H$. Then

$$
\lim \sup _{n \rightarrow \infty}\left\|r_{n}-g\right\|^{2}=\lim \sup _{n \rightarrow \infty}\left\|r_{n}-z\right\|^{2}+\|z-g\|^{2}, \quad \forall g \in H .
$$

Lemma 2.2 ([16]) Let $\left\{a_{n}\right\},\left\{\delta_{n}\right\}$, and $\left\{\gamma_{n}\right\}$ be sequences of nonnegative real numbers satisfying the following relation:

$$
a_{n+1} \leq\left(1+\delta_{n}\right) a_{n}+\gamma_{n}, \quad n \geq n_{0}
$$

where $n_{0}$ is a nonnegative integer. If $\sum \delta_{n}<\infty$ and $\sum \gamma_{n}<\infty$, then $\lim _{n \rightarrow \infty} a_{n}$ exists.

Lemma 2.3 ([4]) Let $X$ be a metric space. If $A, B \in P(X), a \in A$, and $\gamma \geq 0$, then, as a simple consequence of the Hausdorff metric $\Phi$, there exists $b \in B$ such that

$$
d(a, b) \leq \Phi(A, B)+\gamma .
$$

\section{Main results}

We now obtain a demiclosedness property in the sense that if $\left\{r_{n}\right\}_{n=1}^{\infty} \subseteq C$ is such that $\left\{r_{n}\right\}$ weakly converges to $z$ and a sequence $\left\{g_{n}\right\}$ with $g_{n} \in S r_{n}$ and $\left\|r_{n}-g_{n}\right\|=d\left(r_{n}, S r_{n}\right)$ for all $n \in \mathbb{N}$ is such that $\left\{r_{n}-g_{n}\right\}$ strongly converges to 0 , then $0 \in(I-S) z$ (i.e., $z=v$ for some $v \in S z)$.

Proposition 3.1 Let $H$ be a real Hilbert space, and Ca nonempty weakly closed subset of $H$. Let $S: C \subseteq H \rightarrow P(H)$ be a multivalued mapping from $C$ into the family of all proximinal subsets of $H$. If $S$ is a $k$-strictly pseudocontractive mapping of type one, then $(I-S)$ is demiclosed at zero (i.e., the graph of $I-S$ is closed at zero in $\sigma\left(H, H^{*}\right) \times(H,\|\cdot\|)$ or weakly demiclosed at zero). 
Proof We use a method similar to that of the proof of Proposition 3 in [5]. Let $\left\{r_{n}\right\}_{n=1}^{\infty} \subseteq C$ be such that $\left\{r_{n}\right\}$ weakly converges to $z$, and $\left\{g_{n}\right\}$ be a sequence with $g_{n} \in S r_{n}$ and $\| r_{n}-$ $g_{n} \|=d\left(r_{n}, S r_{n}\right)$ for all $n \in \mathbb{N}$ such that $\left\{r_{n}-g_{n}\right\}$ strongly converges to 0 . We prove that $0 \in(I-S) z$ (i.e., $z=v$ for some $v \in S z$ ). Since $\left\{r_{n}\right\}_{n=1}^{\infty}$ converges weakly, it is bounded. Let $q \in S z$ with $\|z-q\|=d(z, S z)$, From the definition of $k$-strictly pseudocontractive and typeone condition on $S$, for each $n \in \mathbb{N}$, we have

$$
\left\|g_{n}-q\right\| \leq \Phi\left(S r_{n}, S z\right)
$$

and

$$
\Phi^{2}\left(S r_{n}, S z\right) \leq\left\|r_{n}-z\right\|^{2}+k\left\|r_{n}-g_{n}-(z-q)\right\|^{2}
$$

Therefore, for each $r \in H$, define $f: H \rightarrow[0, \infty)$ by

$$
f(r):=\limsup _{n \rightarrow \infty}\left\|r_{n}-r\right\|^{2}
$$

Then from Lemma 2.1 we obtain

$$
f(r)=\limsup _{n \rightarrow \infty}\left\|r_{n}-z\right\|^{2}+\|z-r\|^{2}, \quad \forall r \in X .
$$

Thus,

$$
f(r)=f(z)+\|z-r\|^{2}, \quad \forall r \in X .
$$

Therefore,

$$
f(q)=f(z)+\|z-q\|^{2} .
$$

Observe also that

$$
\begin{aligned}
f(q) & =\limsup _{n \rightarrow \infty}\left\|r_{n}-q\right\|^{2} \\
& =\limsup _{n \rightarrow \infty}\left\|r_{n}-g_{n}+\left(g_{n}-q\right)\right\|^{2} \\
& =\limsup _{n \rightarrow \infty}\left\|g_{n}-q\right\|^{2} \\
& \leq \limsup _{n \rightarrow \infty} \Phi^{2}\left(S r_{n}, S z\right) \\
& \leq \limsup _{n \rightarrow \infty}\left[\left\|r_{n}-z\right\|^{2}+k\left\|r_{n}-g_{n}-(z-q)\right\|^{2}\right] \\
& =\limsup _{n \rightarrow \infty}\left\|r_{n}-z\right\|^{2}+k\|(z-q)\|^{2} \\
& =f(z)+k\|z-q\|^{2} .
\end{aligned}
$$

Hence, it follows from (3.3) and (3.4) that $(1-k)\|z-q\|^{2}=0$.

Therefore, $z=q \in S z$. 
We now obtain some strong and weak convergence results for the class of pseudocontractive mappings and $k$-strictly pseudocontractive mappings of Chidume et al. [1], respectively, in Hilbert spaces.

Theorem 3.1 Let $C$ be a nonempty closed and convex subset of a real Hilbert space X. If S : $C \rightarrow P(C)$ is a type-one L-Lipschitzian pseudocontractive mapping from $C$ into the family of all proximinal subsets of $C$ such that $F(S) \neq \emptyset$. Suppose that $S$ satisfies condition (1). Then, the Ishikawa sequence defined by

$$
\left\{\begin{array}{l}
g_{n}=\left(1-\delta_{n}\right) r_{n}+\delta_{n} u_{n}, \\
r_{n+1}=\left(1-\mu_{n}\right) r_{n}+\mu_{n} w_{n},
\end{array}\right.
$$

strongly converges to $p \in F(S)$, where $u_{n} \in S r_{n}$ with $\left\|r_{n}-u_{n}\right\|=d\left(r_{n}, S r_{n}\right), w_{n} \in S g_{n}$ with $\left\|g_{n}-w_{n}\right\|=d\left(g_{n}, S g_{n}\right)$, and $\left\{\mu_{n}\right\}$ and $\left\{\delta_{n}\right\}$ are real sequences satisfying (i) $\liminf _{n \rightarrow \infty} \mu_{n}=$ $\mu>0$, (ii) $0 \leq \mu_{n} \leq \delta_{n}<1$, and (iii) $\sup _{n \geq 1} \delta_{n} \leq \delta \leq \frac{1}{\sqrt{1+L^{2}}+1}$.

Proof Using a method similar to that of the proof of Theorem 4 in [5], we have that

$$
\begin{aligned}
\left\|r_{n+1}-z\right\|^{2}= & \left\|\left(1-\mu_{n}\right) r_{n}+\mu_{n} w_{n}-z\right\|^{2} \\
= & \left\|\left(1-\mu_{n}\right)\left(r_{n}-z\right)+\mu_{n}\left(w_{n}-z\right)\right\|^{2} \\
= & \left(1-\mu_{n}\right)\left\|r_{n}-z\right\|^{2}+\mu_{n}\left\|w_{n}-z\right\|^{2}-\mu_{n}\left(1-\mu_{n}\right)\left\|r_{n}-w_{n}\right\|^{2} \\
\leq & \left(1-\mu_{n}\right)\left\|r_{n}-z\right\|^{2}+\mu_{n} \Phi^{2}\left(S g_{n}, S z\right) \\
& -\mu_{n}\left(1-\mu_{n}\right)\left\|r_{n}-w_{n}\right\|^{2} \\
\leq & \left(1-\mu_{n}\right)\left\|r_{n}-z\right\|^{2}+\mu_{n}\left[\left\|g_{n}-z\right\|^{2}+\left\|g_{n}-w_{n}\right\|^{2}\right] \\
& -\mu_{n}\left(1-\mu_{n}\right)\left\|r_{n}-w_{n}\right\|^{2} \\
= & \left(1-\mu_{n}\right)\left\|r_{n}-z\right\|^{2}+\mu_{n}\left\|g_{n}-z\right\|^{2}+\mu_{n} d^{2}\left(g_{n}, S g_{n}\right) \\
& -\mu_{n}\left(1-\mu_{n}\right)\left\|r_{n}-w_{n}\right\|^{2} .
\end{aligned}
$$

Also,

$$
\begin{aligned}
\left\|g_{n}-w_{n}\right\|^{2}= & \left\|\left(1-\delta_{n}\right) r_{n}+\delta_{n} u_{n}-w_{n}\right\|^{2} \\
= & \left\|\left(1-\delta_{n}\right)\left(r_{n}-w_{n}\right)+\delta_{n}\left(u_{n}-w_{n}\right)\right\|^{2} \\
= & \left(1-\delta_{n}\right)\left\|r_{n}-w_{n}\right\|^{2}+\delta_{n}\left\|u_{n}-w_{n}\right\|^{2} \\
& -\delta_{n}\left(1-\delta_{n}\right)\left\|r_{n}-u_{n}\right\|^{2} .
\end{aligned}
$$

From (3.5) and (3.6) it follows that

$$
\begin{aligned}
\left\|r_{n+1}-z\right\|^{2} \leq & \left(1-\mu_{n}\right)\left\|r_{n}-z\right\|^{2}+\mu_{n}\left\|g_{n}-z\right\|^{2} \\
& +\mu_{n}\left[\left(1-\delta_{n}\right)\left\|r_{n}-w_{n}\right\|^{2}+\delta_{n}\left\|u_{n}-w_{n}\right\|^{2}\right. \\
& \left.-\delta_{n}\left(1-\delta_{n}\right)\left\|r_{n}-u_{n}\right\|^{2}\right] \\
& -\mu_{n}\left(1-\mu_{n}\right)\left\|r_{n}-w_{n}\right\|^{2}
\end{aligned}
$$




$$
\begin{aligned}
\left\|g_{n}-z\right\|^{2} & =\left\|\left(1-\delta_{n}\right) r_{n}+\delta_{n} u_{n}-z\right\|^{2} \\
& =\left\|\left(1-\delta_{n}\right)\left(r_{n}-z\right)+\delta_{n}\left(u_{n}-z\right)\right\|^{2} \\
& =\left(1-\delta_{n}\right)\left\|r_{n}-z\right\|^{2}+\delta_{n}\left\|u_{n}-z\right\|^{2}-\delta_{n}\left(1-\delta_{n}\right)\left\|r_{n}-u_{n}\right\|^{2} \\
& \leq\left(1-\delta_{n}\right)\left\|r_{n}-z\right\|^{2}+\delta_{n} \Phi^{2}\left(S r_{n}, S z\right)-\delta_{n}\left(1-\delta_{n}\right)\left\|r_{n}-u_{n}\right\|^{2} \\
& \leq\left(1-\delta_{n}\right)\left\|r_{n}-z\right\|^{2}+\delta_{n}\left[\left\|r_{n}-z\right\|^{2}+\left\|r_{n}-u_{n}\right\|^{2}\right]-\delta_{n}\left(1-\delta_{n}\right)\left\|r_{n}-u_{n}\right\|^{2} \\
& =\left\|r_{n}-z\right\|^{2}+\delta_{n}^{2}\left\|r_{n}-u_{n}\right\|^{2} .
\end{aligned}
$$

From (3.7) and (3.8) it follows that

$$
\begin{aligned}
\left\|r_{n+1}-z\right\|^{2} \leq & \left(1-\mu_{n}\right)\left\|r_{n}-z\right\|^{2} \\
& +\mu_{n}\left[\left\|r_{n}-z\right\|^{2}+\delta_{n}^{2}\left\|r_{n}-u_{n}\right\|^{2}\right] \\
& +\mu_{n}\left[\left(1-\delta_{n}\right)\left\|r_{n}-w_{n}\right\|^{2}+\delta_{n}\left\|u_{n}-w_{n}\right\|^{2}-\delta_{n}\left(1-\delta_{n}\right)\left\|r_{n}-u_{n}\right\|^{2}\right] \\
& -\mu_{n}\left(1-\mu_{n}\right)\left\|r_{n}-w_{n}\right\|^{2} \\
= & \left(1-\mu_{n}\right)\left\|r_{n}-z\right\|^{2}+\mu_{n}\left\|r_{n}-z\right\|^{2}+\mu_{n} \delta_{n}^{2}\left\|r_{n}-u_{n}\right\|^{2} \\
& +\mu_{n}\left(1-\delta_{n}\right)\left\|r_{n}-w_{n}\right\|^{2}+\mu_{n} \delta_{n}\left\|u_{n}-w_{n}\right\|^{2} \\
& -\mu_{n} \delta_{n}\left(1-\delta_{n}\right)\left\|r_{n}-u_{n}\right\|^{2}-\mu_{n}\left(1-\mu_{n}\right)\left\|r_{n}-w_{n}\right\|^{2} \\
\leq & \left\|r_{n}-z\right\|^{2}+\mu_{n} \delta_{n}^{2}\left\|r_{n}-u_{n}\right\|^{2}+\mu_{n} \delta_{n} \Phi^{2}\left(S r_{n}, S g_{n}\right) \\
& -\mu_{n}\left(\delta_{n}-\mu_{n}\right)\left\|r_{n}-w_{n}\right\|^{2} \\
& -\mu_{n} \delta_{n}\left(1-\delta_{n}\right)\left\|r_{n}-u_{n}\right\|^{2} \\
\leq & \left\|r_{n}-z\right\|^{2}+\mu_{n} \delta_{n}^{2}\left\|r_{n}-u_{n}\right\|^{2}+\mu_{n} \delta_{n}^{3} L^{2}\left\|r_{n}-u_{n}\right\|^{2} \\
& -\mu_{n} \delta_{n}\left(1-\delta_{n}\right)\left\|r_{n}-u_{n}\right\|^{2} \\
& -\mu_{n}\left(\delta_{n}-\mu_{n}\right)\left\|r_{n}-w_{n}\right\|^{2} \\
= & \left\|r_{n}-z\right\|^{2}-\mu_{n} \delta_{n}\left[1-2 \delta_{n}-L^{2} \delta_{n}^{2}\right]\left\|r_{n}-u_{n}\right\|^{2} \\
& -\mu_{n}\left(\delta_{n}-\mu_{n}\right)\left\|r_{n}-w_{n}\right\|^{2} \\
= & \left\|r_{n}-z\right\|^{2}-\mu_{n} \delta_{n}\left[1-2 \delta_{n}-L^{2} \delta_{n}^{2}\right]\left\|r_{n}-u_{n}\right\|^{2} .
\end{aligned}
$$

It then follows from Lemma 2.2 that $\lim _{n \rightarrow \infty}\left\|r_{n}-z\right\|$ exists. Hence, $\left\{r_{n}\right\}$ is bounded, so also are $\left\{u_{n}\right\}$ and $\left\{w_{n}\right\}$. We then have from (3.9)(i), (iii) that

$$
\begin{aligned}
\sum_{n=0}^{\infty} \mu^{2}\left[1-2 \delta-L^{2} \delta^{2}\right]\left\|r_{n}-u_{n}\right\|^{2} & \leq \sum_{n=0}^{\infty} \mu_{n} \delta_{n}\left[1-2 \delta_{n}-L^{2} \delta_{n}^{2}\right]\left\|r_{n}-u_{n}\right\|^{2} \\
& \leq \sum_{n=0}^{\infty}\left[\left\|r_{n}-z\right\|^{2}-\left\|r_{n+1}-z\right\|^{2}\right] \\
& \leq\left\|r_{0}-z\right\|^{2}+D<\infty
\end{aligned}
$$

It then follows that $\lim _{n \rightarrow \infty}\left\|r_{n}-u_{n}\right\|=0$. Since $u_{n} \in S r_{n}$, we have that $d\left(r_{n}, S r_{n}\right) \leq \| r_{n}-$ $u_{n} \| \rightarrow 0$ as $n \rightarrow \infty$. Since $S$ satisfies condition (1), $\lim _{n \rightarrow \infty} d\left(r_{n}, F(S)\right)=0$. Thus, there 
exists a subsequence $\left\{r_{n_{k}}\right\}$ of $\left\{r_{n}\right\}$ such that $\left\|r_{n_{k}}-z_{k}\right\| \leq \frac{1}{2^{k}}$ for some $\left\{z_{k}\right\} \subseteq F(S)$. From (3.9) we have

$$
\left\|r_{n_{k+1}}-z_{k}\right\| \leq\left\|r_{n_{k}}-z_{k}\right\|
$$

We now show that $\left\{z_{k}\right\}$ is a Cauchy sequence in $F(S)$ :

$$
\begin{aligned}
\left\|z_{k+1}-z_{k}\right\| & \leq\left\|z_{k+1}-r_{n_{k+1}}\right\|+\left\|r_{n_{k+1}}-z_{k}\right\| \\
& \leq \frac{1}{2^{k+1}}+\frac{1}{2^{k}} \\
& <\frac{1}{2^{k-1}} .
\end{aligned}
$$

Therefore, $\left\{z_{k}\right\}$ is a Cauchy sequence and converges to some $q \in C$ because $C$ is closed. Now, we have

$$
\left\|r_{n_{k}}-q\right\| \leq\left\|r_{n}-z_{k}\right\|+\left\|z_{k}-q\right\|
$$

Hence, $r_{n_{k}} \rightarrow q$ as $k \rightarrow \infty$. We have

$$
\begin{aligned}
d(q, S q) & \leq\left\|q-z_{k}\right\|+\left\|z_{k}-r_{n_{k}}\right\|+d\left(r_{n_{k}}, S r_{n_{k}}\right)+\Phi\left(S r_{n_{k}}, S q\right) \\
& \leq\left\|q-z_{k}\right\|+\left\|z_{k}-r_{n_{k}}\right\|+d\left(r_{n_{k}}, S r_{n_{k}}\right)+L\left\|r_{n_{k}}-q\right\| .
\end{aligned}
$$

Hence, $q \in S q$, and $\left\{r_{n_{k}}\right\}$ strongly converges to $q$. Since $\lim \left\|r_{n}-q\right\|$ exists, we have that $r_{n}$ strongly converges to $q \in F(S)$.

Theorem 3.2 Let $C$ be a nonempty closed and convex subset of a real Hilbert space $H$. Suppose that $S: C \rightarrow P(C)$ is $k$-strictly pseudocontractive mapping from $C$ into the family of all proximinal subsets of $C$ with $k \in(0,1)$ such that $F(S) \neq \emptyset$. If $S$ is of type one, then the Mann-type sequence defined by

$$
r_{n+1}=\left(1-\mu_{n}\right) r_{n}+\mu_{n} g_{n}
$$

weakly converges to $q \in F(S)$, where $g_{n} \in S r_{n}$ with $\left\|r_{n}-g_{n}\right\|=d\left(r_{n}, S r_{n}\right)$ and $\mu_{n} \subseteq(0,1)$ satisfying (i) $\mu_{n} \rightarrow \mu<1-k$, (ii) $\mu>0$, and (iii) $\sum_{n=1}^{\infty} \mu_{n}\left(1-\mu_{n}\right)=\infty$.

Proof Using the well-known identity and a method similar to that of the proof of Theorem 3 in [5], we have that

$$
\|t r+(1-t) g\|^{2}=t\|r\|^{2}+(1-t)\|g\|^{2}-t(1-t)\|r-g\|^{2},
$$

which holds for all $r, g \in H$ and all $t \in[0,1]$, from which we obtain

$$
\begin{aligned}
\left\|r_{n+1}-z\right\|^{2} & =\left\|\left(1-\mu_{n}\right) r_{n}+\mu_{n} g_{n}-z\right\|^{2} \\
& =\left\|\left(1-\mu_{n}\right)\left(r_{n}-z\right)+\mu_{n}\left(g_{n}-z\right)\right\|^{2} \\
& =\left(1-\mu_{n}\right)\left\|r_{n}-z\right\|^{2}+\mu_{n}\left\|g_{n}-z\right\|^{2}-\mu_{n}\left(1-\mu_{n}\right)\left\|r_{n}-g_{n}\right\|^{2}
\end{aligned}
$$




$$
\begin{aligned}
\leq & \left(1-\mu_{n}\right)\left\|r_{n}-z\right\|^{2}+\mu_{n} \Phi^{2}\left(S r_{n}, S z\right)-\mu_{n}\left(1-\mu_{n}\right)\left\|r_{n}-g_{n}\right\|^{2} \\
\leq & \left(1-\mu_{n}\right)\left\|r_{n}-z\right\|^{2}+\mu_{n}\left[\left\|r_{n}-z\right\|^{2}+k\left\|r_{n}-g_{n}\right\|^{2}\right] \\
& -\mu_{n}\left(1-\mu_{n}\right)\left\|r_{n}-g_{n}\right\|^{2} \\
= & \left\|r_{n}-z\right\|^{2}-\mu_{n}\left(1-\left(\mu_{n}+k\right)\right)\left\|r_{n}-g_{n}\right\|^{2} .
\end{aligned}
$$

It then follows Lemma 2.2 that $\lim _{n \rightarrow \infty}\left\|r_{n}-z\right\|$ exists, and hence $\left\{r_{n}\right\}$ is bounded. Also,

$$
\sum_{n=1}^{\infty} \mu_{n}\left(1-\left(\mu_{n}+k\right)\right)\left\|r_{n}-g_{n}\right\|^{2} \leq\left\|r_{0}-z\right\|^{2} \leq \infty
$$

Since $\mu>0$ from (ii), we have that $\lim _{n \rightarrow \infty}\left\|r_{n}-g_{n}\right\|=0$. Also, since $C$ is closed and $\left\{r_{n}\right\} \subseteq C$ with $\left\{r_{n}\right\}$ bounded, there exists a subsequence $\left\{r_{n t}\right\} \subseteq\left\{r_{n}\right\}$ that weakly converges to some $q \in C$. Also, $\lim _{n \rightarrow \infty}\left\|r_{n}-g_{n}\right\|=0$ implies that $\lim _{n \rightarrow \infty}\left\|r_{n_{t}}-g_{n_{t}}\right\|=0$. Since $(I-S)$ is weakly demiclosed at zero, we have that $q \in S q$. Since $H$ satisfies Opial's condition [15], we have that $\left\{r_{n}\right\}$ weakly converges to $q \in F(S)$.

We now have the following corollaries with proofs easily following from the definition and Theorems 3.1 and 3.2, respectively.

Corollary 3.1 ([10]) Let $C$ be a nonempty closed and convex subset of a real Hilbert space $H$. Suppose that $S: C \rightarrow P(C)$ is a type-one quasi-nonexpansive mapping from $C$ into the family of all proximinal subsets of $C$. If $(I-S)$ satisfies Proposition 3.1, then the Mann-type sequence defined by

$$
r_{n+1}=\left(1-\mu_{n}\right) r_{n}+\mu_{n} g_{n}
$$

weakly converges to $q \in F(S)$, where $g_{n} \in S r_{n}$ with $\left\|r_{n}-g_{n}\right\|=d\left(r_{n}, S r_{n}\right)$, and $\mu_{n}$ is a real sequence in $(0,1)$ satisfying $\mu_{n} \rightarrow \mu \in(0,1)$.

Corollary 3.2 ([10]) Let $C$ be a nonempty closed and convex subset of a real Hilbert space $H$. Suppose that $S: C \rightarrow P(C)$ is a type-one nonexpansive mapping from $C$ into the family of all proximinal subsets of $C$ such that $F(S) \neq \emptyset$. Then the Mann-type sequence defined by

$$
r_{n+1}=\left(1-\mu_{n}\right) r_{n}+\mu_{n} g_{n}
$$

weakly converges to $q \in F(S)$, where $g_{n} \in S r_{n}$ with $\left\|r_{n}-g_{n}\right\|=d\left(r_{n}, S r_{n}\right)$ and $\mu_{n} \subseteq(0,1)$ satisfying $\mu_{n} \rightarrow \mu \in(0,1)$.

Concluding Remark It is not clear if Theorem 3.1 and Theorem 3.2 will still hold if the classes of pseudocontractive and $k$-strictly pseudocontractive mappings considered are replaced with the classes $k$-strictly pseudocontractive-type and pseudocontractive-type mappings, respectively, considered by Isiogugu [5]. 


\section{Acknowledgements}

The author is a post doctoral fellow at the School of Mathematics, Statistics and Computer Sciences, University of Kwazulu Natal, South Africa. She is grateful to the University for the scholarship, making their facilities available, and for hospitality. She is also grateful to the University of Nigeria Nsukka for granting her study leave.

Received: 24 August 2015 Accepted: 22 April 2016 Published online: 04 May 2016

\section{References}

1. Chidume, CE, Chidume, CO, Djitté, N, Minjibir, MS: Convergence theorems for fixed points multivalued strictly pseudocontractive mappings in Hilbert spaces. Abstr. Appl. Anal. 2013, Article ID 629468 (2013)

2. Mann, WR: Mean value methods in iterations. Proc. Am. Math. Soc. 4, 506-510 (1953)

3. Ishikawa, S: Fixed points by a new iteration method. Proc. Am. Math. Soc. 44, 147-150 (1974)

4. Isiogugu, FO, Osilike, MO: Convergence theorems for new classes of multivalued hemicontractive-type mappings. Fixed Point Theory Appl. 2014, 93 (2014)

5. Isiogugu, FO: Demiclosedness principle and approximation theorems for certain classes of multivalued mappings in Hilbert spaces. Fixed Point Theory Appl. 2013, Article ID 61 (2013)

6. Song, Y, Wang, H: Erratum to 'Mann and Ishikawa iterative processes for multivalued mappings in Banach spaces' [Comput. Math. Appl. 54 (2007), 872-877]. Comput. Math. Appl. 55, 2999-3002 (2008)

7. Shahzad, N, Zegeye, H: On Mann and Ishikawa iteration schemes for multi-valued mappings in Banach spaces. Nonlinear Anal. 71(3-4), 838-844 (2009)

8. Song, Y, Cho, YJ: Some notes on Ishikawa iteration for multivalued mappings. Bull. Korean Math. Soc. 48(3), 575-584 (2011). doi:10.4134/BKMS.2011.48.3.575

9. Khan, SH, Yildirim, I: Fixed points of multivalued nonexpansive mappings in Banach spaces. Fixed Point Theory Appl. 2012, Article ID 73 (2012). doi:10.1186/1687-1812-2012-73

10. Isiogugu, FO, Pillay, P, Osilike, MO: On Approximation of Fixed Points of Multi-valued quasi-Nonexpansive Mappings in Hilbert Spaces. Accepted for publication

11. Sastry, KPR, Babu, GVR: Convergence of Ishikawa iterates for a multivalued mapping with a fixed point. Czechoslov. Math. J. 55, 817-826 (2005)

12. Panyanak, B: Mann and Ishikawa iteration processes for multivalued mappings in Banach spaces. Comput. Math. Appl. 54, 872-877 (2007)

13. Garcia-Falset, J, Lorens-Fuster, E, Suzuki, T: Fixed point theory for a class of generalised nonexpansive mappings. J. Math. Anal. Appl. 375, 185-195 (2011)

14. Dozo, EL: Multivalued nonexpansive mappings and Opial's condition. Proc. Am. Math. Soc. 38(2)، 286-292 (1973)

15. Opial, Z: Weak convergence of the sequence of successive approximations for nonexpansive mappings. Bull. Am. Math. Soc. 73, 591-597 (1967)

16. Osilike, MO, Aniagbaoso, SC, Akuchu, BG: Fixed points of asymptotically demicontractive mappings in arbitrary Banach spaces. Panam. Math. J. 12(2), 77-88 (2002)

\section{Submit your manuscript to a SpringerOpen ${ }^{\circ}$ journal and benefit from:}

- Convenient online submission

Rigorous peer review

- Immediate publication on acceptance

- Open access: articles freely available online

- High visibility within the field

- Retaining the copyright to your article 